\title{
Impact of oral health conditions on the quality of life of preschool children and their families: a cross-sectional study
}

Monalisa Cesarino Gomes ${ }^{1}$, Tassia Cristina de Almeida Pinto-Sarmento ${ }^{1}$, Edja Maria Melo de Brito Costa ${ }^{1}$, Carolina Castro Martins², Ana Flávia Granville-Garcia ${ }^{1 *}$ and Saul Martins Paiva ${ }^{2}$

\begin{abstract}
Background: Dental caries, traumatic dental injury (TDI) and malocclusion are common oral health conditions among preschool children and can have both physical and psychosocial consequences. Thus, it is important to measure the impact these on the oral health-related quality of life (OHRQoL) of children. The aim of the present study was to assess the impact of oral health conditions on the OHRQoL of preschool children and their families.

Methods: A preschool-based, cross-sectional study was carried out with 843 preschool children in the city of Campina Grande, Brazil. Parents/caregivers answered the Brazilian Early Childhood Oral Health Impact Scale and a questionnaire addressing socio-demographic data as well as the parent's/caregiver's perceptions regarding their child's health. Clinical exams were performed by three researchers who had undergone a calibration process for the diagnosis of dental caries, $\mathrm{TDI}$ and malocclusion ( $K=0.83-0.85)$. Hierarchical Poisson regression was employed to determine the strength of associations between oral health conditions and OHRQoL $(a=5 \%)$. The multivariate model was run on three levels obeying a hierarchical approach from distal to proximal determinants: 1) socio-demographic data; 2) perceptions of health; and 3) oral health conditions.

Results: The prevalence of impact from oral health conditions on OHRQoL was 32.1\% among the children and 26.2\% among the families. The following variables were significantly associated with a impact on OHRQoL among the children: birth order of child ( $P R=1.430 ; 95 \%$ Cl: 1.045-1.958), parent's/caregiver's perception of child's oral health as poor $(P R=1.732 ; 95 \% \mathrm{Cl}: 1.399-2.145)$, cavitated lesions (PR $=2.596 ; 95 \% \mathrm{Cl}: 1.982-3.400)$ and $\mathrm{TDI}(\mathrm{PR}=1.413 ; 95 \% \mathrm{Cl}$ : 1.161-1.718). The following variables were significantly associated with a impact on OHRQoL among the families: parent's/caregiver's perception of child's oral health as poor ( $P R=2.116 ; 95 \% \mathrm{Cl}$ : 1.624-2.757), cavitated lesions ( $P R=2.809 ; 95 \% \mathrm{Cl}: 2.009-3.926)$ and type of TDI ( $P R=2.448 ; 95 \% \mathrm{Cl}: 1.288-4.653)$.
\end{abstract}

Conclusion: Cavitated lesions and TDI exerted a impact on OHRQoL of the preschool children and their families. Parents'/caregivers' perception of their child's oral health as poor and the birth order of the child were predictors of a greater impact on OHRQoL.

Keywords: Quality of life, Dental caries, Malocclusion, Tooth injuries, Preschool child

\footnotetext{
* Correspondence: anaflaviagg@hotmail.com

'Postgraduate Program in Dentistry, State University of Paraiba (UEPB), 1325/

410 Capitão João Alves de Lira, 58428-800 Campina Grande, PB, Brazil

Full list of author information is available at the end of the article
} 


\section{Background}

Oral health conditions can have a negative impact on the functional, social and psychological wellbeing of young children and their families, causing pain and discomfort for the child $[1,2]$. Assessing the impact of oral health on the life quality of children can improve communication between patients, parents and the dental team and can provide an outcome measure for clinicians to assess the quality of care. Moreover, the evaluation of oral health-related quality of life (OHRQoL) can assist in the assessment of treatment needs, the prioritisation of care and the evaluation of the outcomes of treatment strategies and initiatives [3-5].

The interest in the assessment of OHRQoL among children has grown in recent years, which is a major improvement, as children in many communities around the world are affected by dental caries, traumatic dental injury (TDI) and malocclusion [2,4-9]. Recent studies carried out in Brazil have shown high prevalence rates of adverse oral conditions, especially in areas with social inequalities, such as the area in which the present study was conducted [10-12].

The Early Childhood Oral Health Impact Scale (ECOHIS) was developed to assess the impact of oral health conditions on the quality of life of preschool children (aged 2 to 5 years) and their families and has been validated in Portuguese for use on Brazilian populations $[1,13,14]$. This scale is a proxy measure that considers parents/caregivers to be fundamental in the treatment decision-making process and perceptions regarding children's oral health conditions $[1,13]$. Moreover evidence in the fields of child development and psychology indicates that children less than six years of age are incapable of accurately recalling day-to-day events after more than 24 hours [15].

Studies evaluating the impact of oral health conditions on OHRQoL are often based on non-randomised [5-7] convenience samples [9,16,17]. Moreover, most studies use dichotomised variables (presence/absence of oral health conditions) $[2,9,16,17]$. Few studies have stratified the variables based on the severity of TDI and types of malocclusion [5,7] and all studies have evaluated dental caries using the WHO criteria, which does not discriminate cavitated dental caries and the initial stages of dental caries (e.g., white spots). No study in the literature has evaluated the severity of dental caries based on new diagnostic index for dental caries: the International Caries Detection and Assessment System (ICDAS), which is an internationally accepted caries detection system that allows the assessment of initial carious lesions (white spots) on the enamel and active lesions in the dentine. This system is based on the combined knowledge of the clinical appearance of the lesion, whether the lesion is in a plaque stagnation area and tactile sensation (texture) when a round-tipped probe is gently drawn across the surface of the tooth $[18,19]$. No study has evaluated the impact of white spots and cavitations on OHRQoL. Furthermore, the present investigation is a unique representative, randomised study with a two-stage sampling method and hierarchical analysis to evaluate the impact of the severity of TDI, type of malocclusion, white spots and cavitated dental caries on OHRQoL.

The aim of the present study was to evaluate the impact of oral health conditions on the OHRQoL of preschool children aged three to five years and their families in a representative, preschool-based sample.

\section{Methods}

\section{Sample characteristics}

A cross-sectional study was carried out involving a randomly selected sample of 843 male and female children aged three to five years enrolled in private and public preschools in the city of Campina Grande, Brazil. The participants were selected from a total population of 12,705 children in this age group. Campina Grande (estimated population: 386,000 ) is an industrialised city in northeast Brazil and is divided into six administrative districts. The city has a Human Development Index of $0.72[20]$.

The percentage distribution of three-to-five-year-old preschool children in each administrative district was calculated from information provided by the municipal Board of Education. To ensure representativeness, the sample was stratified according to administrative district and type of institution (two-phase sampling method). Preschools were randomly selected from each administrative district in the first phase and preschool children were randomly selected from each preschool in the second phase. Sample distribution was proportional to the total population enrolled in private and public preschools in each administrative district of the city. The sample size was calculated based on a $4 \%$ margin of error, a 95\% confidence level and a correction factor of 1.2 to compensate for the design effect [21]. As the prevalence of impact on OHRQoL was unknown, a prevalence rate of $50 \%$ was considered to increase the power and because this value gives the largest sample regardless of the actual prevalence [22]. Eighteen of the 127 public preschools and 15 of the 122 private preschools were randomly selected. The minimum sample size was estimated at 720 preschool children, to which an additional $20 \%$ was added to compensate for possible losses, giving a total sample of 864 preschool children.

The present study received approval from the Human Research Ethics Committee of the State University of Paraíba (Brazil) under process number 00460133000-11 in compliance with Resolution 196/96 of the Brazilian National Health Council. All participants' rights were 
protected. Parents/caregivers read and signed a statement of informed consent prior to the children's participation.

\section{Eligibility criteria}

To be included in the study, the children needed to be between three and five years of age, enrolled in a preschool and free of systemic diseases (based on the reports of the parents/caregivers). Only reports of parents/ caregivers were considered for systemic disease; no systemic examination was conducted. The exclusion criteria were the presence of one or more erupted permanent teeth, a history of orthodontic treatment and caregivers not fluent in Brazilian.

\section{Training and calibration exercise}

The training and calibration exercise consisted of two steps (theoretical and clinical). The theoretical step involved a discussion of the criteria for the diagnosis of dental caries, TDI, malocclusion and an analysis of photographs. A specialist in paediatric dentistry (gold standard in this theoretical framework) coordinated this step, instructing three general dentists on how to perform the examination. The clinical step was performed at a randomly selected preschool that was not part of the main sample. Each dentist examined 50 previously selected preschool children between three and five years of age. Inter-examiner agreement was tested by comparing each examiner ( $\mathrm{K}=0.83$ to 0.88 ). After a seven-day interval, the examinations were performed a second time for the determination of intra-examiner agreement ( $\mathrm{K}=0.85$ to 0.90). Data analysis involved Cohen's Kappa coefficient on a tooth-by-tooth basis. As the Kappa coefficients were very good [23], the examiners were considered capable of conducting the epidemiological study.

\section{Pilot study}

A pilot study was conducted to test the methodology and comprehension of the questionnaires. The children in the pilot study $(n=40)$ were not included in the main sample. As there were no misunderstandings regarding the questionnaires or the methodology, no changes to the data collection process were deemed necessary.

\section{Non-clinical data collection}

The acquisition of the non-clinical data involved the administration of the Brazilian version of the Early Childhood Oral Health Impact Scale (B-ECOHIS) and questionnaires addressing socio-demographic data and parents'/caregivers' perceptions regarding their child's health. Parents/caregivers were previously contacted to attend a meeting at the preschools, at which they were informed regarding the objectives of the study. Parents/ caregivers who agreed to participate signed a statement of informed consent and were then instructed to answer the B-ECOHIS and a questionnaire addressing sociodemographic data. For the B-ECOHIS, the parents/ caregivers were instructed to consider the child's entire lifetime experience of oral health conditions and treatment. All questionnaires were filled out by the parents/ caregivers and returned at the end of the meeting.

The B-ECOHIS is used for the evaluation of parents'/ caregivers' perceptions regarding the impact of oral health conditions on the OHRQoL of preschool children and their families. This measure has been employed in previous studies $[1,13,14]$ and is divided into two sections (Child Impact and Family Impact), with a total of six subscales and 13 items. The subscales on the Child Impact section are symptoms (1 item), function (4 items), psychology (2 items) and self-image/social interaction ( 2 items). The subscales on the Family Impact section are parental distress (2 items) and family function (2 items). Each item has six response options: $0=$ never; 1 = hardly ever; $2=$ sometimes; 3 =often; $4=$ very often; and 5 = "I don't know". Questionnaires with two or more unanswered items on the Child Impact section or one or more unanswered item on the Family Impact section were considered incomplete and were excluded from the analysis. The scores are totalled for each section ("don't know" responses are not counted). The total score ranges from 0 to 36 points on the Child Impact section and 0 to 16 points on the Family Impact section, with higher scores indicating greater impact $[1,13]$. In the present study, negative impact on child and family OHRQoL was recorded when at least one response of "sometimes", "often" or "very often" was chosen, whereas responses of "never" and "hardly ever" were considered indicative of an absence of negative impact, as recommended by the creators of the original ECOHIS [15].

The following socio-demographic variables were analysed: sex and age of child; parent's/guardian's age; mother's schooling; number of residents in the home; child's birth order among siblings; type of preschool (public or private); and monthly household income (categorised based on the monthly minimum salary in Brazil, which was equal to US\$312.50).

Parent's/caregiver' perceptions regarding their child's general and oral health status were evaluated based on answers to the following question: In general, how would you describe your child's general health/oral health? The response options were 1) very good, 2) good, 3) fair, 4) poor and 5) very poor. For statistical purposes, these answers were dichotomised as good (codes 1 and 2) and poor (codes 3, 4 and 5) [2].

\section{Clinical data collection}

After the return of the questionnaires and signed statement of informed consent, clinical examinations were 
performed at the preschools by three dentists who had undergone the training and calibration exercise. Prior to the exam, each child received a kit containing a toothbrush, toothpaste and dental floss to remove bacterial plaque from the teeth and facilitate the diagnosis. The child was then seated in front of the examiner. Light was provided by a portable lamp positioned on the examiner's head (Petzl Zoom head lamp, Petzl America, Clearfield, UT, USA). The dentists used individual protection equipment, a sterilised mouth mirror (PRISMA ${ }^{\circ}$, São Paulo, SP, Brazil), sterilised Williams probe (WHO-621, Trinity ${ }^{\circ}$, Campo Mourão, PA, Brazil) and gauze to dry the teeth.

Dental caries was diagnosed using the International Caries Detection and Assessment System (ICDAS II) [18], which is a scoring system ranging from 0 (absence of dental caries) to 6 . Due to the epidemiological nature of the present study, code 1 was not used, as drying of the teeth was performed with gauze rather than compressed air. Code 2 was used for white spots and codes $\geq$ 3 determined different degrees of cavitations. For statistical purposes, dental caries was dichotomised as absent (code 0) or present (code $\geq 2$ ) [18]. Untreated dental caries was also considered in the evaluation of the impact of cavitated lesions in OHRQoL. This variable was categorised as absent/white spot (codes 0 and 2), cavitated anterior teeth (codes $\geq 3$ ), cavitated posterior teeth (codes $\geq 3$ ), cavitated anterior and posterior teeth (codes $\geq 3$ ). It is noteworthy that code 4 represents those lesions where there are underlying shadows indicating that the carious demineralization has progressed into dentin [18], however not all codes 4 are cavitated but in this study were included as cavitated lesions.

TDI was diagnosed as enamel fracture, enamel + dentine fracture, complicated crown fracture, extrusive luxation, lateral luxation, intrusive luxation and avulsion [24]. A visual inspection was also made of tooth colouration. TDI was recorded in the presence of any type of TDI or tooth discolouration. Malocclusion was recorded in the presence of at least one of the following conditions: increased overbite $(>2 \mathrm{~mm})$, increased overjet $(>2 \mathrm{~mm}$ ), anterior open bite, anterior crossbite and posterior crossbite $[25,26]$. Following the exam, a fluoridated varnish was applied to the teeth and children with dental caries or other dental needs were sent for treatment.

\section{Statistical analysis}

Descriptive statistics were first performed to characterise the sample. The chi-square test was used to test associations between oral health conditions and sociodemographic data and the Bonferroni correction was used for variables with more than two categories. Bivariate Poisson regression analysis with robust variance was used to determine associations between the independent variables and negative impact on the OHRQoL of the preschool children and their families $(\mathrm{p}<0.05)$. The multivariate model obeyed a hierarchical approach from distal to proximal determinants: 1) socio-demographic data, 2) parent's/caregiver's perception of child's health and 3) oral health conditions (Figure 1) [27]. The backward stepwise procedure was used to incorporate variables that achieved a p-value $<0.20$ in the bivariate analysis as well as variables considered epidemiological determinants on each level. Variables with a p-value < 0.05 in the adjusted analysis were maintained in the final regression model. Interactions among dental caries, TDI and malocclusion were tested using Wald's test. Variance inflation factors were calculated to determine the existence of collinearity among the predictors in the adjusted model. The data were organised and analysed with the aid of the Statistical Package for Social Sciences (SPSS for Windows, version 20.0, SPSS Inc, Chicago, IL, USA).

\section{Results}

A total of 843 pairs of preschool children and their parents/ caregivers participated in the present study, corresponding to $97.5 \%$ of the total determined by the sample size calculation. The loss of 21 children was due to a lack of cooperation during the exam $(n=6)$, incomplete questionnaires $(n=11)$ and absence from preschool on the days scheduled for the clinical examinations $(n=4)$.

Table 1 displays the oral health conditions distributed according to the socio-demographic data of the sample. The chi-square test revealed that, among the three oral conditions, only cavitated lesions were significantly associated with age, type of school, mother's schooling and monthly household income. More children with cavitated lesions were aged five years (56.8\%), studied at public preschools $(58.6 \%)$, had mothers with $\leq$ eight years of schooling (62.4\%) or came from families that earned up to the minimum wage (61.1\%) compared to children with white spots or without dental caries. Parents'/caregivers' perceptions of general and oral health were poor among $81.0 \%$ and $66.5 \%$ of the sample, respectively.

The prevalence of negative impact on OHRQoL was $32.1 \%$ among the children and $26.2 \%$ among the families. Scores of 0 (floor effect) were found on $58.6 \%$ and $69.6 \%$ of the Child Impact and Family Impact sections of the B-ECOHIS, respectively (i.e., $58.6 \%$ and $69.6 \%$ of the parents/caregivers reported no impacts). No ceiling effect was found for either section (i.e., scores of 36 and 16 on the Child and Family Impact sections, respectively). The maximum score was 31 on the Child Impact section and 14 on the Family Impact section (Table 2). Table 2 also displays the mean, standard deviation, median, minimum and maximum total B-ECOHIS scores and subscales scores. The items with the highest means were "reported pain", "felt guilty" and "been upset". 


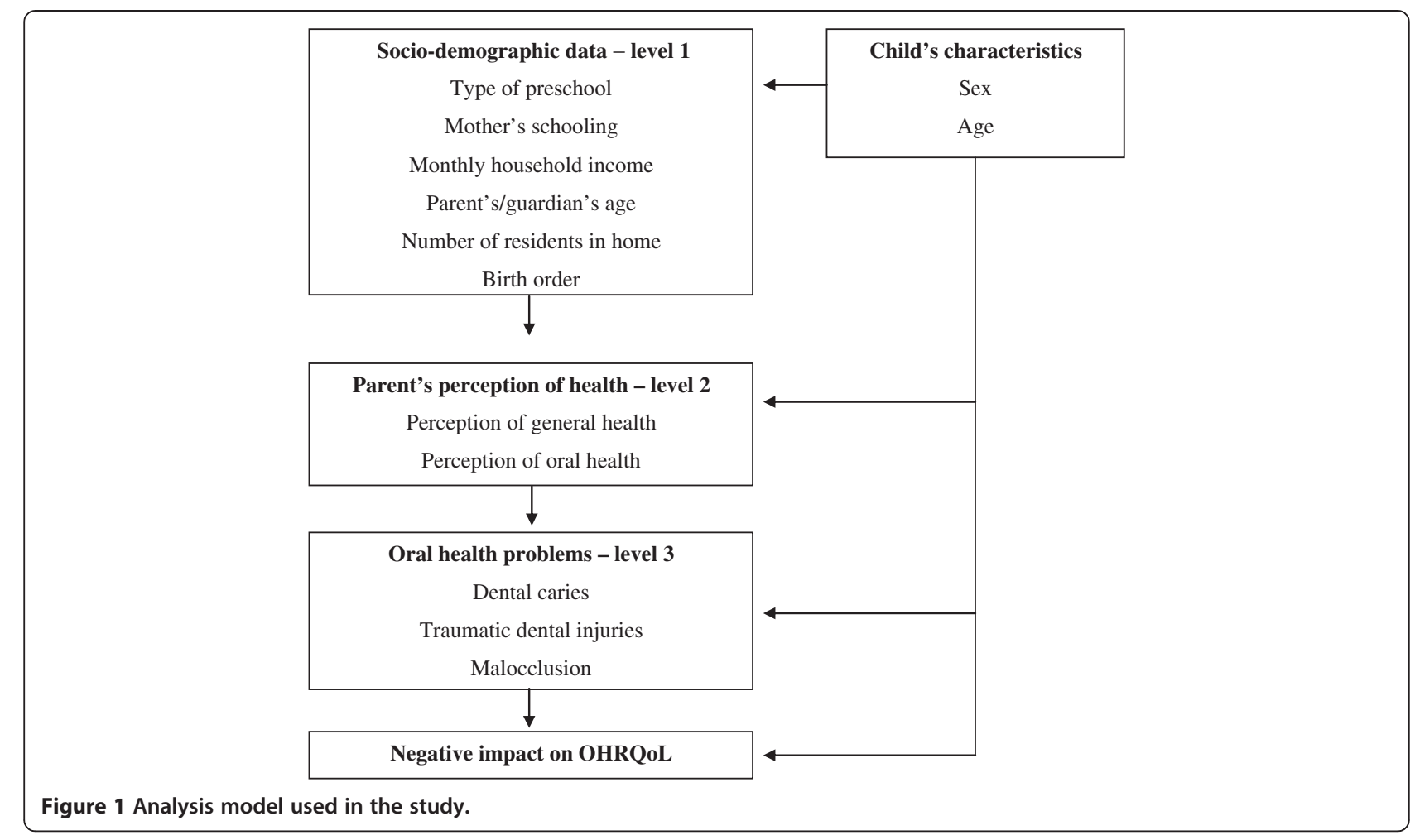

Table 1 Frequency of clinical variables according to socio-demographic data of preschool children analysed

\begin{tabular}{|c|c|c|c|c|c|c|c|}
\hline \multirow[t]{2}{*}{ Variable } & \multicolumn{3}{|c|}{ Dental caries } & \multicolumn{2}{|c|}{ TDI } & \multicolumn{2}{|c|}{ Malocclusion } \\
\hline & $\begin{array}{l}\text { Absent* } \\
\text { n (\%) }\end{array}$ & $\begin{array}{l}\text { White spots* } \\
\text { n (\%) }\end{array}$ & $\begin{array}{l}\text { Cavitations* } \\
\mathrm{n}(\%)\end{array}$ & $\begin{array}{l}\text { Absent } \\
\text { n (\%) }\end{array}$ & $\begin{array}{l}\text { Present } \\
\mathrm{n}(\%)\end{array}$ & $\begin{array}{l}\text { Absent } \\
\text { n (\%) }\end{array}$ & $\begin{array}{l}\text { Present } \\
\mathrm{n}(\%)\end{array}$ \\
\hline \multicolumn{8}{|l|}{ Sex } \\
\hline Female & $125(30.7)^{\mathrm{A}}$ & $82(20.1)^{\mathrm{A}}$ & $200(49.1)^{\mathrm{A}}$ & $275(67.9)^{\mathrm{A}}$ & $130(32.1)^{\mathrm{A}}$ & $141(34.8)^{\mathrm{A}}$ & $264(65.2)^{A}$ \\
\hline Male & $158(36.2)^{\mathrm{A}}$ & $76(17.4)^{\mathrm{A}}$ & $202(46.3)^{\mathrm{A}}$ & $278(64.1)^{\mathrm{A}}$ & $156(35.9)^{\mathrm{A}}$ & $152(35.0)^{\mathrm{A}}$ & $282(65.0)^{\mathrm{A}}$ \\
\hline \multicolumn{8}{|l|}{ Age } \\
\hline 3 years & $107(38.9)^{\mathrm{A}}$ & $61(22.2)^{\mathrm{A}}$ & $107(38.9)^{B}$ & $176(64.0)^{\mathrm{A}}$ & $99(36.0)^{A}$ & $85(30.9)^{A}$ & $190(69.1)^{\mathrm{A}}$ \\
\hline 4 years & $103(30.8)^{\mathrm{A}}$ & $69(20.7)^{\mathrm{A}}$ & $162(48.5)^{B}$ & $226(68.2)^{A}$ & $106(31.9)^{\mathrm{A}}$ & $115(34.6)^{\mathrm{A}}$ & $217(65.4)^{\mathrm{A}}$ \\
\hline 5 years & $73(31.1)^{\mathrm{A}}$ & $28(12.0)^{\mathrm{A}}$ & $133(56.8)^{\mathrm{B}}$ & $151(65.1)^{\mathrm{A}}$ & $81(34.9)^{\mathrm{A}}$ & $93(40.1)^{\mathrm{A}}$ & $139(59.9)^{\mathrm{A}}$ \\
\hline \multicolumn{8}{|l|}{ Type of preschool } \\
\hline Public & $111(24.3)^{\mathrm{A}}$ & $78(17.1)^{\mathrm{A}}$ & $267(58.6)^{\mathrm{B}}$ & $305(67.3)^{\mathrm{A}}$ & $148(32.7)^{\mathrm{A}}$ & $163(36.0)^{\mathrm{A}}$ & $290(64.0)^{\mathrm{A}}$ \\
\hline Private & $172(44.4)^{\mathrm{A}}$ & $80(20.7)^{A}$ & $135(34.9)^{\mathrm{B}}$ & $248(64.2)^{\mathrm{A}}$ & $138(35.8)^{\mathrm{A}}$ & $130(33.7)^{\mathrm{A}}$ & $256(66.3)^{A}$ \\
\hline \multicolumn{8}{|l|}{ Mother's schooling } \\
\hline$\leq 8$ years of study & $100(25.8)^{\mathrm{A}}$ & $46(11.9)^{\mathrm{A}}$ & $242(62.4)^{B}$ & $262(68.1)^{\mathrm{A}}$ & $123(31.9)^{\mathrm{A}}$ & $133(34.5)^{\mathrm{A}}$ & $252(65.5)^{\mathrm{A}}$ \\
\hline$>8$ years of study & $183(40.5)^{\mathrm{A}}$ & $111(24.6)^{\mathrm{A}}$ & $158(35.0)^{B}$ & $289(64.1)^{\mathrm{A}}$ & $162(35.9)^{\mathrm{A}}$ & $160(35.5)^{\mathrm{A}}$ & $291(64.5)^{\mathrm{A}}$ \\
\hline \multicolumn{8}{|c|}{ Monthly household income } \\
\hline$\leq 1$ minimum salary & $108(24.4)^{\mathrm{A}}$ & $64(14.5)^{\mathrm{A}}$ & $270(61.1)^{B}$ & $299(68.0)^{A}$ & $141(32.0)^{\mathrm{A}}$ & $166(37.7)^{\mathrm{A}}$ & $274(62.3)^{A}$ \\
\hline$>1$ minimum salary & $157(43.4)^{\mathrm{A}}$ & $84(23.2)^{\mathrm{A}}$ & $121(33.4)^{B}$ & $229(63.6)^{A}$ & $131(36.4)^{\mathrm{A}}$ & $113(31.4)^{\mathrm{A}}$ & $247(68.6)^{A}$ \\
\hline TOTAL & $283(33.6)$ & 158 (18.7) & $402(47.7)$ & $553(65.9)$ & 286 (34.1) & 293 (34.9) & $546(65.1)$ \\
\hline
\end{tabular}

${ }^{*}$ Chi-square test with Bonferroni correction; Different capital letters denote significantly different results $(p<0.05)$. 
Table 2 Prevalence of impact on oral health-related quality of life and B-ECOHIS scores among preschool children

\begin{tabular}{|c|c|c|c|c|}
\hline Subscales, Items & SCORE Mean \pm SD & Median & Minimum-Maximum & Impact N (\%) \\
\hline ECOHIS total $(0-52)$ & $3.60 \pm 6.10$ & 0 & $0-38$ & $349(41.4)$ \\
\hline Child Impact & $2.41 \pm 4.41$ & 0 & $0-31$ & $271(32.1)$ \\
\hline Reported pain & $0.61 \pm 0.99$ & 0 & $0-4$ & $195(23.1)$ \\
\hline Had difficulty drinking hot or cold beverages & $0.36 \pm 0.82$ & 0 & $0-4$ & $110(13.1)$ \\
\hline Had difficulty eating some foods & $0.37 \pm 0.85$ & 0 & $0-4$ & $112(13.3)$ \\
\hline Had difficulty pronouncing words & $0.22 \pm 0.72$ & 0 & $0-4$ & $66(7.8)$ \\
\hline Missed preschool, day care or school & $0.13 \pm 0.49$ & 0 & $0-3$ & $34(4.1)$ \\
\hline Had trouble sleeping & $0.20 \pm 0.64$ & 0 & $0-4$ & $56(6.6)$ \\
\hline Been irritable or frustrated & $0.31 \pm 0.78$ & 0 & $0-4$ & $95(11.3)$ \\
\hline Avoided smiling or laughing & $0.11 \pm 0.49$ & 0 & $0-4$ & $26(3.1)$ \\
\hline Avoided talking & $0.10 \pm 0.45$ & 0 & $0-4$ & $27(3.2)$ \\
\hline Family Impact & $1.23 \pm 2.31$ & 0 & $0-14$ & $221(26.2)$ \\
\hline Been upset & $0.41 \pm 0.92$ & 0 & $0-4$ & $126(15.0)$ \\
\hline Felt guilty & $0.49 \pm 0.97$ & 0 & $0-4$ & $157(18.7)$ \\
\hline Taken time off work & $0.17 \pm 0.59$ & 0 & $0-4$ & $56(6.7)$ \\
\hline Financial impact & $0.16 \pm 0.60$ & 0 & $0-4$ & $46(5.4)$ \\
\hline
\end{tabular}

In the final hierarchical Poisson regression model, the following variables were significantly associated with a negative impact on OHRQoL among the children: child's order of birth, parent's/caregiver's perception of child's oral health as poor, cavitated dental caries and TDI (Table 3). The following variables were significantly associated with a negative impact on OHRQoL among the families: parent's/caregiver's perception of child's oral health as poor, cavitated dental caries and greater severity of TDI (Table 4).

\section{Discussion}

The present study evaluated the impact of dental caries, TDI and malocclusion on the OHRQoL of preschool children using the Brazilian Portuguese version of the ECOHIS. The occurrence of cavitated lesions and TDI was found to cause a negative impact on the OHRQoL of preschool children and their families, whereas different types of malocclusion did not have this effect. Moreover, this is the first study to perform a hierarchical approach, which stratifies the impact of the severity of TDI, different types of malocclusion, different stages of dental caries and the teeth affected as risk factors that exert an influence on quality of life. Such an approach allows an analysis of interrelationships among factors rather than making the strict statistical associations commonly found in multivariate methods [27].

Cavitated lesions were associated with OHRQoL among the children and families due to the fact that parents/caregivers recognise an oral health problem when it becomes evident or when it is manifested in the form of pain $[28,29]$. Indeed, the parents/caregivers reported greater impact on the items "reported pain", "difficulty drinking hot or cold beverages", "difficulty eating some foods" and "been irritable". These findings indicate symptoms related to more serious oral health problems, such as untreated dental caries [30]. Severe dental caries can result in parents/caregivers missing days of work and greater financial expenditures as well as feelings of guilt, with a consequent negative impact on the OHRQoL of the family $[17,28]$. Moreover, the greater participation of women in the job market and consequent reduction in the role mothers play in raising their children [31] may have contributed to the greater frequency of the items "felt guilty" and "been upset", as suggested in previous studies $[2,8,17]$. It should be stressed that dental caries was diagnosed in the present study using the criteria of the ICDAS-II, which detects the early manifestations of this condition [18]. This may explain why the presence of dental caries when considering data on white spots was not associated with OHRQoL, as such lesions often go unperceived by parents/caregivers and do not cause pain. Cavitated teeth have been associated to a negative impact on OHRQoL in previous investigations $[2,5,6,17,29]$, although the location of the lesions was not evaluated in the studies cited. Cavitated lesions on anterior teeth were not associated with a negative impact on OHRQoL, likely due to the nature of these lesions, which were not very severe, and the lesser importance given to aesthetics in the age group analysed [32]. However, when posterior teeth and both posterior and anterior teeth were analysed, significant associations were found with a negative impact on OHRQoL, possibly because cavities on posterior teeth are generally 
Table 3 Hierarchical Poisson regression for impact on OHRQoL of children and independent variables

Variable

\begin{tabular}{cc}
\multicolumn{3}{c}{ Impact on child's } & OHRQoL \\
\hline Present & Absent \\
n (\%) & n (\%)
\end{tabular}

\begin{tabular}{c} 
Bivariate \\
\hline Unadjusted \\
\hline PR $^{*}$ \\
\hline p-value \\
\hline$(95 \% \mathrm{Cl})$
\end{tabular}

\begin{tabular}{c} 
Multivariate \\
\hline Adjusted \\
\hline PR + \\
\hline p-value \\
\hline$(95 \% \mathrm{Cl})$
\end{tabular}

\section{Sex}

Female

Male

Age

3 years

4 years

5 years

\section{$1^{\text {st }}$ level}

\section{Type of preschool}

Public

Private

\section{Mother's schooling}

$\leq 8$ years of study

$>8$ years of study

132 (32.4)

275 (67.6)

$139(31.9)$

$297(68.1)$

0.864

$1.017(0.836-1.238)$

$71(25.8)$

204 (74.2)

95 (28.4)

$105(44.9)$

239 (71.6)

$129(55.1)$

0.470

$<0.001$

$1.102(0.847-1.433)$

$1.738(1.360-2.222)$

Monthly household income

$\leq 1$ minimum salary

$>1$ minimum salary

Parent's/guardian's age

$\leq 30$ years

$>30$ years

Number of residents in home

$<6$

$\geq 6$

Birth order

Only child

Oldest child

Middle child

Youngest child

$2^{\text {nd }}$ level

Perception of general health

Good

Poor

201 (29.6)

479 (70.4)

70 (44.0)

$89(56.0)$

120 (21.4)

440 (78.6)

$151(53.5)$

131 (46.5)

$<0.001$

1.00

1.00

Poor

$3^{\text {rd }}$ level

Dental caries

Absent

46 (16.3)

$225(40.2)$
237 (83.7) 335 (59.8)
$<0.001$

1.451 (1.181-1.784)

1.00

$<0.001$

$1.510(1.239-1.841)$

1.00

$1.686(1.357-2.094)$

1.00

1.079 (0.883-1.319)

1.00

1.00

$1.342(1.061-1.697)$

1.00

1.00

$$
<0.001
$$

$1.782(1.309-2.425)$

0.025

1.430 (1.045-1.958)

0.006

$1.602(1.143-2.243)$

0.316

$1.183(0.852-1.641)$

1.520 (1.166-1.981)

0.106

$1.228(0.957-1.575)$
Present 
Table 3 Hierarchical Poisson regression for impact on OHRQoL of children and independent variables (Continued)

\begin{tabular}{|c|c|c|c|c|c|c|}
\hline \multicolumn{7}{|l|}{ Cavitated lesions } \\
\hline Absent/white spots & $77(17.5)$ & $364(82.5)$ & & 1.00 & & 1.00 \\
\hline Cavitated anterior teeth & $17(29.3)$ & $41(70.7)$ & 0.024 & $1.679(1.072-2.628)$ & 0.146 & $1.422(0.885-2.287)$ \\
\hline Cavitated posterior teeth & $82(44.6)$ & $102(55.4)$ & $<0.001$ & $2.552(1.970-3.307)$ & $<0.001$ & $2.011(1.518-2.664)$ \\
\hline Cavitated anterior and posterior teeth & $95(59.4)$ & $65(40.6)$ & $<0.001$ & $3.401(2.675-4.323)$ & $<0.001$ & $2.596(1.982-3.400)$ \\
\hline \multicolumn{7}{|l|}{ TDI } \\
\hline Absent & $168(30.4)$ & $385(69.6)$ & & 1.00 & & 1.00 \\
\hline Present & $100(35.0)$ & $186(65.0)$ & 0.173 & $1.151(0.940-1.409)$ & 0.001 & $1.413(1.161-1.718)$ \\
\hline \multicolumn{7}{|l|}{ Type of TDI } \\
\hline Discolouration & $38(39.2)$ & $59(60.8)$ & 0.071 & $1.285(0.979-1.688)$ & - & - \\
\hline Avulsion and/or luxation & $4(36.4)$ & $7(63.6)$ & 0.661 & $1.193(0.542-2.628)$ & - & - \\
\hline Enamel + dentine fracture & $16(38.1)$ & $26(61.9)$ & 0.276 & $1.250(0.836-1.868)$ & - & - \\
\hline Enamel fracture and without trauma & $210(30.5)$ & $479(69.5)$ & & 1.00 & - & - \\
\hline \multicolumn{7}{|l|}{ Malocclusion } \\
\hline Absent & $95(32.4)$ & $198(67.6)$ & 0.827 & $1.023(0.833-1.258)$ & - & - \\
\hline Present & $173(31.7)$ & $373(68.3)$ & & 1.00 & - & - \\
\hline \multicolumn{7}{|l|}{ Anterior crossbite } \\
\hline Absent & $256(31.5)$ & $557(68.5)$ & & 1.00 & - & - \\
\hline Present & $9(39.1)$ & $14(60.9)$ & 0.413 & $1.243(0.739-2.090)$ & - & - \\
\hline \multicolumn{7}{|l|}{ Anterior open bite } \\
\hline Absent & $201(31.1)$ & $446(68.9)$ & & 1.00 & - & - \\
\hline Present & $58(32.8)$ & $119(67.2)$ & 0.663 & $1.055(0.830-1.341)$ & - & - \\
\hline \multicolumn{7}{|l|}{ Posterior crossbite } \\
\hline Absent & $229(31.3)$ & $503(68.7)$ & & 1.00 & - & - \\
\hline Unilateral & $30(32.3)$ & $63(67.7)$ & 0.848 & $1.031(0.754-1.411)$ & - & - \\
\hline Bilateral & $5(55.6)$ & $4(44.4)$ & 0.058 & $1.776(0.980-3.217)$ & - & - \\
\hline \multicolumn{7}{|l|}{ Increased overbite } \\
\hline Absent & $224(33.6)$ & $442(66.4)$ & 0.009 & $1.518(1.112-2.073)$ & - & - \\
\hline Present & $35(22.2)$ & $123(77.8)$ & & 1.00 & - & - \\
\hline \multicolumn{7}{|l|}{ Increased overjet } \\
\hline Absent & $144(30.6)$ & $326(69.4)$ & & 1.00 & - & - \\
\hline Present & $121(33.1)$ & $245(66.9)$ & 0.455 & $1.079(0.884-1.317)$ & - & - \\
\hline
\end{tabular}

*Unadjusted Poisson regression for independent variables and impact on child's quality of life.

**Variables incorporated in multivariate model $(p<0.20)$ : sex, age, type of preschool, mother's schooling, monthly household income, number of residents in home, child's birth order, parent's/caregiver's perception of child's general health, parent's/caregiver's perception of child's oral health, dental caries, untreated dental caries, traumatic dental injury, type of traumatic dental injury, malocclusion, posterior crossbite and increased overbite.

***For dental caries, the cut-off point was code $\geq 2$; for cavitated lesions, absent/white spots (codes $\leq 2$ ) and cavitated tooth (codes $\geq 3$ ) were considered. †Hierarchical Poisson regression: Level 1 adjusted for child's characteristics and socio-demographic variables; Level 2 adjusted for child's characteristics, sociodemographic variables and parent's/caregiver's perception of child's health; Level 3 adjusted for child's characteristics, socio-demographic variables, parent's/ caregiver's perception of child's health and oral health problems (dental caries, traumatic dental injuries and malocclusion).

more severe and associated with reports of pain and difficulty eating $[28,30]$.

Cavitated lesions were associated with socio-demographic variables (lower income, lower educational level of the mother, enrolment at a public preschool and children aged five years) in comparison to children with white spots or without dental caries. This demonstrates the importance of socio-demographic data regarding the use of dental services [33,34]. Some studies have found a greater frequency of impact on the OHRQoL of preschool children from families with a lower socioeconomic status $[2,6,17]$. However, no socioeconomic variable remained associated with the negative impact on quality of life in the present investigation, which is in agreement with data reported in a previous study [5]. This finding suggests that oral health conditions can exert an impact on the 
Table 4 Hierarchical Poisson regression for impact on OHRQoL of family and independent variables

Variable

$\begin{array}{cc}\text { Present } & \text { Absent } \\ n(\%) & n(\%)\end{array}$

Sex

Female

Male

Age

3 years

4 years

5 years

$1^{\text {st }}$ level

Type of preschool

Public

Private

Mother's schooling

$\leq 8$ years of study

$>8$ years of study

Monthly household income

$\leq 1$ minimum salary

$>1$ minimum salary

Parent's/guardian's age

$\leq 30$ years

$>30$ years

Number of residents in home

$<6$

$\geq 6$

Birth order

Only child

Oldest child

Middle child

Youngest child

$2^{\text {nd }}$ level

Perception of general health

Good

Poor

Perception of oral health

Good

Poor

$3^{\text {rd }}$ level

Dental caries

Absent

Present

\begin{tabular}{c} 
Bivariate \\
\hline Unadjusted \\
\hline PR $^{*}$ \\
\hline p-value \\
\hline$(95 \% \mathrm{Cl})$
\end{tabular}

1.00

106 (26.0)

301 (74.0)

$115(26.4)$

$321(73.6)$

$66(24.0)$

209 (76.0)

85 (25.4)

70 (29.9)

131 (28.7)

325 (71.3)

297 (76.7)

117 (30.2)

$271(69.8)$

$104(23.0)$

348(77.0)

132 (29.9)

82 (22.7)

$310(70.1)$

$280(77.3)$

$\begin{array}{lccc}120(28.4) & 302(71.6) & 0.080 & 1.232(0.975-1.557) \\ 93(23.1) & 310(76.9) & & 1.00 \\ 176(25.2) & 523(74.8) & & 1.00 \\ 43(33.3) & 86(66.7) & 0.046 & 1.324(1.005-1.744) \\ & & & 1.00 \\ 55(20.9) & 208(79.1) & & 1.516(1.068-2.152) \\ 39(31.7) & 84(68.3) & 0.020 & 1.241(0.832-1.853) \\ 27(26.0) & 77(74.0) & 0.290 & 1.343(1.006-1.792) \\ 98(28.1) & 251(71.9) & 0.046 & \end{array}$

\section{7 (23.1)}

$523(76.9)$

61 (38.4)

$98(61.6)$

$472(84.3)$

149 (52.8)

$<0.001$

1.00

\begin{tabular}{c} 
Multivariate \\
\hline Adjusted \\
\hline PR $\dagger$ \\
\hline p-value \\
\hline$(95 \% \mathrm{Cl})$
\end{tabular}

(95\% Cl) 
Table 4 Hierarchical Poisson regression for impact on OHRQoL of family and independent variables (Continued)

\begin{tabular}{|c|c|c|c|c|c|c|}
\hline \multicolumn{7}{|l|}{ Cavitated lesions } \\
\hline Absent/white spots & $55(12.5)$ & $386(87.5)$ & & 1.00 & & 1.00 \\
\hline Cavitated anterior teeth & $14(24.1)$ & $44(75.9)$ & 0.013 & $1.935(1.152-3.252)$ & 0.079 & $1.586(0.949-2.651)$ \\
\hline Cavitated posterior teeth & $73(39.7)$ & $111(60.3)$ & $<0.001$ & $3.181(2.345-4.315)$ & $<0.001$ & $2.380(1.679-3.372)$ \\
\hline Cavitated anterior and posterior teeth & $79(49.4)$ & $81(50.6)$ & $<0.001$ & $3.959(2.954-5.306)$ & $<0.001$ & $2.809(2.009-3.926)$ \\
\hline \multicolumn{7}{|l|}{ TDI } \\
\hline Absent & $143(25.9)$ & $410(74.1)$ & & 1.00 & - & - \\
\hline Present & $74(25.9)$ & $212(74.1)$ & 0.996 & $1.001(0.786-1.274)$ & - & - \\
\hline \multicolumn{7}{|l|}{ Type of TDI } \\
\hline Discolouration & $32(33.0)$ & $65(67.0)$ & 0.080 & $1.322(0.968-1.805)$ & 0.054 & $1.326(0.995-1.766)$ \\
\hline Avulsion and/or luxation & $4(36.4)$ & $7(63.6)$ & 0.352 & $1.457(0.660-3.217)$ & 0.006 & $2.448(1.288-4.653)$ \\
\hline Enamel + dentine fracture & $9(21.4)$ & $33(78.6)$ & 0.614 & $0.858(0.474-1.554)$ & 0.877 & $1.048(0.582-1.885)$ \\
\hline Enamel fracture and without trauma & $172(25.0)$ & $517(75.0)$ & & 1.00 & & 1.00 \\
\hline \multicolumn{7}{|l|}{ Malocclusion } \\
\hline Absent & $81(27.6)$ & $212(72.4)$ & 0.386 & $1.110(0.877-1.405)$ & - & - \\
\hline Present & $136(24.9)$ & $410(75.1)$ & & 1.00 & - & - \\
\hline \multicolumn{7}{|l|}{ Anterior crossbite } \\
\hline Absent & $207(25.5)$ & $606(74.5)$ & & 1.00 & - & - \\
\hline Present & $9(39.1)$ & $14(60.9)$ & 0.107 & $1.537(0.911-2.593)$ & - & - \\
\hline \multicolumn{7}{|l|}{ Anterior open bite } \\
\hline Absent & $166(25.7)$ & $481(74.3)$ & 0.950 & $1.009(0.759-1.341)$ & - & - \\
\hline Present & $45(25.4)$ & $132(74.6)$ & & 1.00 & - & - \\
\hline \multicolumn{7}{|l|}{ Posterior crossbite } \\
\hline Absent & $548(74.9)$ & $184(25.1)$ & & 1.00 & - & - \\
\hline Unilateral & $27(29.0)$ & $66(71.0)$ & 0.408 & $1.155(0.821-1.625)$ & - & - \\
\hline Bilateral & $5(55.6)$ & $4(44.4)$ & 0.009 & $2.210(1.216-4.017)$ & - & - \\
\hline \multicolumn{7}{|l|}{ Increased overbite } \\
\hline Absent & $185(27.8)$ & $481(72.2)$ & 0.006 & $1.688(1.164-2.449)$ & - & - \\
\hline Present & $26(16.5)$ & 132(83.5) & & 1.00 & - & - \\
\hline \multicolumn{7}{|l|}{ Increased overjet } \\
\hline Absent & $128(27.2)$ & $342(72.8)$ & 0.298 & $1.133(0.896-1.432)$ & - & - \\
\hline Present & $88(24.0)$ & $278(76.0)$ & & 1.00 & - & - \\
\hline
\end{tabular}

*Unadjusted Poisson regression for independent variables and impact on family's quality of life.

**Variables incorporated in multivariate model $(p<0.20)$ : sex, age, type of preschool, mother's schooling, monthly household income, parent's/guardian's age, number of residents in home, child's birth order, parent's/caregiver's perception of child's general health, parent's/caregiver's perception of child's oral health, dental caries, untreated dental caries, traumatic dental injury, type of traumatic dental injury, malocclusion, anterior crossbite, posterior crossbite and increased overbite.

***For dental caries, the cut-off point was code $\geq 2$; for cavitated lesions, absent/white spots (codes $\leq 2$ ) and cavitated tooth (codes $\geq 3$ ) were considered. †Hierarchical Poisson regression: Level 1 adjusted for child's characteristics and socio-demographic variables; Level 2 adjusted for child's characteristics, sociodemographic variables and parent's/caregiver's perception of child's health; Level 3 adjusted for child's characteristics, socio-demographic variables, parent's/ caregiver's perception of child's health and oral health problems (dental caries, traumatic dental injuries and malocclusion).

quality of life of children regardless of one's socioeconomic status.

While a previous investigation found an association between malocclusion and impact on OHRQoL [5], the majority of studies found no such association [2,7,9,17,35], which is in agreement with the present findings. However, TDI had a negative impact on the OHRQoL of the preschool children and cases of avulsion and/or luxation were predictors of a negative impact on the OHRQoL of the families. This type of oral health problem may require a considerable amount of time on the part of the family due to the urgency of relieving the pain symptoms and the limitations that may arise $[5,9,28]$. Parents/caregivers generally perceive a negative impact on quality of life when clinical signs are involved, such as tooth discolouration, which can exert a psychosocial impact on the child [8]. However, some 
studies have found no association between TDI and OHRQoL $[2,8,17]$. This may be due to the type of TDI considered in the analysis, as negative impact generally only occurs in more serious cases [7,9,28].

Birth order of the child was a predictor of a greater negative impact on OHRQoL among the children, likely because financial resources and attention from parents/ caregivers are shared among the siblings as more children are born into the family [36,37]. Indeed, a greater frequency of dental caries is found among children in large families [38].

Parents'/caregivers' perception of their child's oral health was associated with a negative impact on the OHRQoL of both the children and families. Perceptions of parents/caregivers regarding their child's oral health plays an important role in the determination of the negative impact on OHRQoL [39], as the health of preschool children depends on parental/caregiver knowledge regarding health care [40].

The present study has the limitations inherent to the cross-sectional design and the answers on the questionnaires may have been subject to information bias. However, a number of measures were taken to diminish the occurrence of such bias, such as the use of a validated questionnaire and the execution of a pilot study. Thus, it is possible to extrapolate the findings, since the present investigation was a representative, preschool-based study. Longitudinal studies are needed to clarify the relationship of causality and allow establishment of public policies aimed at reducing the impact of oral health conditions on the OHRQoL of preschool children and their families.

\section{Conclusion}

Cavitated lesions on anterior and posterior teeth, traumatic dental injuries and parents'/caregivers' perception of their child's oral health as poor are determinants of a negative impact on the OHRQoL of preschool children and their families. While white spots were not associated with impact on OHRQoL, it is important to treat such cases to prevent the progression to cavitation.

\section{Abbreviations}

OHRQOL: Oral health-related quality of life; TDI: Traumatic dental injury; ECOHIS: Early Childhood Oral Health Impact Scale; B-ECOHIS: Brazilian version of the Early Childhood Oral Health Impact Scale; ICDAS: International Caries Detection and Assessment System.

\section{Competing interests}

The authors declare that they have no competing interests.

\section{Authors' contributions}

MCG was responsible for the analysis and interpretation of the data, helped the statistical analysis and drafted the manuscript. TCAPS was responsible for the conception and study design, acquisition and interpretation of data. EMMBC performed data acquisition and drafted the manuscript. CCM performed the analysis and interpretation of the data and a critical review of the manuscript. AFGG was responsible for conception design, analysis and interpretation of the data and a critical review of the manuscript. SMP was responsible for the conception and study design and performed the final critical review. All authors read and approved the final manuscript.

\section{Acknowledgments}

This study was supported by the State University of Paraíba (UEPB), the Brazilian Coordination of Higher Education, Ministry of Education (CAPES), the Research Foundation of the State of Minas Gerais (FAPEMIG) and the National Council for Scientific and Technological Development (CNPQ), Brazil.

\section{Author details}

${ }^{1}$ Postgraduate Program in Dentistry, State University of Paraiba (UEPB), 1325/ 410 Capitão João Alves de Lira, 58428-800 Campina Grande, PB, Brazil. ${ }^{2}$ Department of Paediatric Dentistry and Orthodontic, Federal University of Minas Gerais (UFMG), Belo Horizonte, MG, Brazil.

Received: 19 January 2014 Accepted: 15 April 2014

Published: 18 April 2014

\section{References}

1. Scarpelli AC, Oliveira BH, Tesch FC, Leão AT, Pordeus IA, Paiva SM: Psychometric properties of the Brazilian version of the Early Childhood Oral Health Impact Scale (B-ECOHIS). BMC Oral Health 2011, 11:19.

2. Scarpelli AC, Paiva SM, Viegas CM, Carvalho AC, Ferreira FM, Pordeus IA: Oral health-related quality of life among Brazilian preschool children. Community Dent Oral Epidemiol 2013, 41:336-344.

3. Sheiham A, Maizels JE, Cushing AM: The concept of need in dental care. Int Dent J 1982, 32:265-270.

4. McGrath C, Broder H, Wilson-Genderson M: Assessing the impact of oral health on the life quality of children: implications for research and practice. Community Dent Oral Epidemiol 2004, 32:81-85.

5. Kramer PF, Feldens CA, Ferreira SH, Bervian J, Rodrigues PH, Peres MA: Exploring the impact of oral diseases and disorders on quality of life of preschool children. Community Dent Oral Epidemiol 2013, 41:327-235.

6. Martins-Júnior PA, Vieira-Andrade RG, Corrêa-Faria P, Oliveira-Ferreira F, Marques LS, Ramos-Jorge ML: Impact of early childhood caries on the oral health-related quality of life of preschool children and their parents. Caries Res 2013, 47:211-218.

7. Abanto J, Tello G, Bonini GC, Oliveira LB, Murakami C, Bönecker M: Impact of traumatic dental injuries and malocclusions on quality of life of preschool children: a population-based study. Int J Paediatr Dent, in press.

8. Viegas CM, Scarpelli AC, Carvalho AC, Ferreira FM, Pordeus IA, Paiva SM: Impact of traumatic dental injury on quality of life among Brazilian preschool children and their families. Pediatr Dent 2012, 36:300-307.

9. Aldrigui JM, Abanto J, Carvalho TS, Mendes FM, Wanderley MT, Bönecker M, Raggio DO: Impact of traumatic dental injuries and malocclusions on quality of life of young children. Health Qual Life Outcomes 2011, 9:78.

10. Feitosa S, Colares V, Pinkham J: The psychosocial effects of severe caries in 4-year-old children in Recife, Pernambuco, Brazil. Cad Saude Publica 2005, 21:1550-1556.

11. Sousa RV, Pinto Monteiro AK, Martins CC, Granville-Garcia AF, Paiva SM: Malocclusion and socioeconomic indicators in primary dentition. Braz Oral Res 2013, 28:54-60.

12. Siqueira MB, Gomes MC, Oliveira AC, Martins CC, Granville-Garcia AF, Paiva SM: Predisposing factors for traumatic dental injury in primary teeth and seeking of post-trauma care. Braz Dent J 2013, 24:647-654.

13. Tesch FC, Oliveira BH, Leão A: Semantic equivalence of the Brazilian version of the Early Chilhood Oral Health Impact Scale. Cad Saude Publica 2008, 24:1897-1909.

14. Martins-Júnior PA, Ramos-Jorge J, Paiva SM, Marques LS, Ramos-Jorge ML: Validations of the Brazilian version of the early childhood oral health impact scale (ECOHIS). Cad Saude Publica 2012, 28:367-374.

15. Pahel BT, Rozier RG, Slade GD: Parental perceptions of children's oral health: The Early Childhood Oral Health Impact Scale (ECOHIS). Health Qual Life Outcomes 2007, 5:6.

16. Wong HM, McGrath CP, King NM, Lo EC: Oral health-related quality of life in Hong Kong preschool children. Caries Res 2011, 45:370-376.

17. Abanto J, Carvalho TS, Mendes FM, Wanderley MT, Bonecker M, Raggio DP: Impact of oral diseases and disorders on oral health-related quality of life of preschool children. Community Dent Oral Epidemiol 2011, 39:105-114. 
18. Ismail Al, Sohn W, Tellez M, Amaya A, Sen A, Hasson H: The International Caries Detection and Assessment System (ICDAS): an Integrated System for Measuring Dental Caries. Community Dent Oral Epidemiol 2007, 35:170-178.

19. Diniz MB, Rodrigues JA, Hug I, Cordeiro RC, Lussi A: Reproducibility and accuracy of the ICDAS-II for occlusal caries detection. Community Dent Oral Epidemiol 2009, 37:399-404.

20. Brazilian Institute of Geography and Statistics: First Results of the 2010 Census. [http://cidades.ibge.gov.br/xtras/home.php]

21. David J, Astrøm AN, Wang NJ: Factors associated with traumatic dental injuries among 12-year-old schoolchildren in South India. Dent Traumatol 2009, 25:500-505.

22. Browner WS, Newman TB, Hulley SB: Estimating sample size and power: applications and exemples. In Designing Clinical Research. 3rd edition. Edited by Hulley SB, Cummings SR, Browner WS, Grady DG, Newman TB. Philadelphia: Lippincott and Williams \& Wilkins; 2007:65-94.

23. Altman DG: Practical Statistics for Medical Research. 2nd edition. London: Chapman and Hall; 2006

24. Andreasen JO, Andreasen FM, Andersson L: Textbook and Color Atlas of Traumatic Injuries to the Teeth. 4th edition. Oxford: Blackwell; 2007.

25. Foster TD, Hamilton MC: Occlusion in the primary dentition. Study of children at 21 to 3 years of age. Br Dent J 1969, 126:76-79.

26. Grabowski R, Stahl F, Gaebel M, Kundt G: Relationship between occlusal findings and orofacial myofunctional status in primary and mixed dentition. Part I: Prevalence of malocclusions. J Orofac Orthop 2007, 68:26-37.

27. Victora CG, Huttly SR, Fuchs SC, Olinto MTA: The role of conceptual frameworks in epidemiological analysis: a hierarchical approach. Int J Epidemiol 1997, 26:224-227.

28. Abanto J, Paiva SM, Raggio DP, Celiberti P, Aldriqui JM, Bönecker M: The impact of dental caries and trauma in children on family quality of life. Community Dent Oral Epidemiol 2012, 40:323-331.

29. Lee GHM, McGrath C, Yiu CKY, King NM: A comparison of a generic and oral health-specific measure in assessing the impact of early childhood caries on quality of life. Community Dent Oral Epidemiol 2010, 38:333-339.

30. Kiwanuka SN, Astrømn AN: Self reported dental pain and associated factors in Ugandan schoolchildren. Nor Epidemiol 2005, 15:175-182.

31. Arora A, Bedros D, Bhole S, Do LG, Scott J, Blinkhorn A, Schwarz E: Child and family health nurses' experiences of oral health of preschool children: a qualitative approach. J Public Health Dent 2012, 72:149-155.

32. Bönecker M, Abanto J, Tello G, Oliveira LB: Impact of dental caries on preschool children's quality of life: an update. Braz Oral Res 2012, 26:103-107.

33. Kramer PF, Ardenghi TM, Ferreira S, Fischer LA, Cardoso L, Feldens CA: Use of dental services by preschool children in Canela, Rio Grande do Sul State, Brazil. Cad Saude Publica 2008, 24:150-156.

34. Machry RV, Tuchtenhagen S, Agostini BA, Teixeira CRS, Piovesan C, Mendes FM, Ardenghi TM: Socioeconomic and psychosocial predictors of dental healthcare use among Brazilian preschool children. BMC Oral Health 2013, 13:60

35. Carvalho AC, Paiva SM, Viegas CM, Scarpelli AC, Ferreira FM, Pordeus IA: Impact of Malocclusion on Oral Health-Related Quality of Life among Brazilian Preschool Children: a Population-Based Study. Braz Dent J 2013, 24:655-661.

36. Hertwig R, Davis JN, Sulloway FJ: Parental investment: how an equity motive can produce inequality. Psychol Bull 2002, 128:728-745.

37. Hearton TB, Forste R, Hoffmann JP, Flake D: Cross-national variation in family influences on child health. Soc Sci Med 2005, 60:97-108.

38. Wellappuli N, Amarasena N: Influence of family structure on dental caries experience of preschool children in Sri Lanka. Caries Res 2012, 46:208-212.

39. Wandera M, Kayondo J, Engebretsen IM, Okullo I, Astrom AN: Factors associated with caregivers' perception of children's health and oral health status: a study of 6- to 36-month-olds in Uganda. Int J Paediatr Dent 2009, 19:251-262.

40. Thikkurissy S, Allen PH, Smiley MK, Casamassimo PS: Waiting for the pain to get worse: characteristics of a pediatric population with acute dental pain. Pediatr Dent 2012, 34:289-294.

\section{doi:10.1186/1477-7525-12-55}

Cite this article as: Gomes et al:: Impact of oral health conditions on the quality of life of preschool children and their families: a cross-sectional study. Health and Quality of Life Outcomes 2014 12:55. 